\title{
HIGH GAIN OBSERVER DESIGN FOR INDUCTION MOTOR WITH NON LINEAR MAGNETIC CHARACTERISTIC
}

\author{
H. Ouadi, F. Giri, J. De Leon-Morales, L. Dugard \\ A GREYC, ISMRA, 14050 Caen, France \\ giri@greyc.ismra.
}

\begin{abstract}
State estimators for induction motors are generally designed based on standard simplified models, assuming linear magnetic characteristics. Since they are actually nonlinear, especially for high power machines, the mentioned state estimators are likely not able to achieve the estimation accuracy they have been designed for. In this paper, a new state estimator is developed for a (uniform air-gap) AC machine, based on a more accurate model that appropriately accounts for the saturation feature in the magnetic characteristics. The proposed estimator is a high-gain full-order nonlinear observer designed using Lyapunov stability tools. The resulting estimation errors are shown to asymptotically vanish, if their initial values belong to a well defined attraction region. Supremacy of the new observer over standard ones is illustrated by simulation using a 7.5 KW AC machine. Copyright $(\mathbb{C} 2005$
\end{abstract}

Keywords: : Induction motors, observer, Lyapunov stability.

\section{INTRODUCTION}

Real-time measurement of the flux is necessary in most of proposed AC machine controllers. The use of physical sensors raises problems (for robustness consideration). So, an important research activity has been devoted to the design of flux observers. The first solutions (see e.g. Lubineau et al, 1999) were developed based on simplified assumptions namely, linear magnetic characteristics and constant (or slowly varying) rotor speed. Under these assumptions, the model of the induction motor becomes linear and, therefore, observability analysis and observer design may be dealt with, using standard linear theory tools (pole placement design, Luenberger and Kalman observers). Interesting contributions came later (see e.g. Barbot et al, 2000; De Leon et al, 2001) proposing nonlinear observers developed without supposing a constant rotor speed.
The proposed observers have been designed using different approaches such as high gain, sliding mode and dynamic state feedback. However, even in these contributions, the machine magnetic characteristics are still supposed to be linear (which it is not the case in real-life situations). This assumption can be approached, in practical applications by constraining (through an appropriate control loop) the norm flux to be constant or to stay (even in transient periods) in the linear part of the magnetic characteristic (otherwise, the expected performances of the above observers cannot be achieved). However, these two strategies do not allow the motor to work in optimal conditions of efficiency and dynamic performances.

In this paper, a new state observer is proposed for estimating the rotor flux (and the stator currents) in induction motors. Designed from a more accurate model accounting for nonlinear machine magnetic 
characteristics (Ouadi et al, 2004a), the new observer proves to be efficient even for large flux variations (those belonging to the nonlinear part of the magnetic characteristics). Then, if the machine is driven by a regulator using this observer, it is possible to control the flux on a large domain of variation. This strategy allows improving the power factor, the efficiency, or limiting the current absorbed by the machine.

This paper is organized as follows: in Section 2, a non linear observation model is built-up based on the accurate model developed in (Ouadi et al, 2004a). In Section 3, a full-order high-gain observer is designed using Lyapunov stability tools. It is shown that the state estimation error asymptotically vanishes within a well specified attraction region. In Section 4, the supremacy of the new observer over standard ones is illustrated by simulation, using the model developed and experimentally validated in (Ouadi et al, 2004a) for a $7.5 \mathrm{KW}$ AC machine.

\section{OBSERVATION MODEL DEVELOPMENT}

A model that accounts for the nonlinear feature of the magnetic characteristic, in induction motors, has been developed in (Ouadi et al, 2004a). It proved to be accurate through an experimental validation on a 7.5 KW motor and, hence, will be referred as Experimentally Validated Model (EVM). It is used here as a simulator of the true machine. However, such an EVM is not convenient for designing observers and controllers because it involves many parameters that depend on the machine magnetic state. In (Ouadi et al, 2004a), a simplified version of the EVM is presented. It consists in gathering both stator and rotor leakage inductances, leading to a unique equivalent inductance denoted $\mathrm{L}_{\text {seq }}$, placed at the stator, see (Leonhard. W, 1985). The observation model thus obtained is the following:

$$
\begin{aligned}
& \frac{\mathrm{d} \phi_{\mathrm{rd}}}{\mathrm{dt}}=-\mathrm{kL}_{\mathrm{seq}} \delta(\mathrm{t}) \phi_{\mathrm{rd}}+\mathrm{a}_{1} \mathrm{i}_{\mathrm{sd}}+\left(\omega_{\mathrm{s}}-\omega\right) \phi_{\mathrm{rq}} \\
& \frac{\mathrm{d} \phi_{\mathrm{rq}}}{\mathrm{dt}}=-\mathrm{kL}_{\mathrm{seq}} \delta(\mathrm{t}) \phi_{\mathrm{rq}}+\mathrm{a}_{1} \mathrm{i}_{\mathrm{sq}}-\left(\omega_{\mathrm{s}}-\omega\right) \phi_{\mathrm{rd}} \\
& \frac{\mathrm{di} \mathrm{s}_{\mathrm{sd}}}{\mathrm{dt}}=\delta(\mathrm{t}) \phi_{\mathrm{rd}}+\mathrm{a}_{3} \omega \phi_{\mathrm{rq}}-\mathrm{a}_{2} \mathrm{i}_{\mathrm{sd}}+\omega_{\mathrm{s}} \mathrm{i}_{\mathrm{sq}}+\frac{1}{\mathrm{~L}_{\mathrm{sq}}} \mathrm{v}_{\mathrm{sd}} \\
& \frac{\mathrm{di}_{\mathrm{sq}}}{\mathrm{dt}}=-\mathrm{a}_{3} \omega \phi_{\mathrm{rd}}+\delta(\mathrm{t}) \phi_{\mathrm{rq}}-\omega_{\mathrm{s}} \mathrm{i}_{\mathrm{sd}}-\mathrm{a}_{2} \mathrm{i}_{\mathrm{sq}}+\frac{1}{\mathrm{~L}_{\mathrm{seq}}} \mathrm{v}_{\mathrm{sq}} \\
& \frac{\mathrm{d} \omega}{\mathrm{dt}}=\frac{1}{\mathrm{~J}}\left(\phi_{\mathrm{rd}} \mathrm{i}_{\mathrm{sq}}-\phi_{\mathrm{rq}} \mathrm{i}_{\mathrm{sd}}\right)-\frac{\mathrm{T}_{\mathrm{L}}}{\mathrm{J}}
\end{aligned}
$$

where, see (Ouadi et al, 2004b):

- $\delta(t)$, the only model parameter depending on the machine magnetic state, is given by:

$$
\delta(\mathrm{t})=\mathrm{W}\left(\Phi_{\mathrm{r}}\right)
$$

with $\mathrm{W}($.) the polynomial approximation of the varying model parameter $\delta(\mathrm{t})$, defined by:

$$
\mathrm{W}\left(\Phi_{\mathrm{r}}\right)=\mathrm{b}_{0}+\mathrm{b}_{1} \Phi_{\mathrm{r}}+\ldots+\mathrm{b}_{\mathrm{p}} \Phi_{\mathrm{r}}^{\mathrm{p}}
$$

and $\Phi_{\mathrm{r}}$ the amplitude of the rotor flux $\phi_{\mathrm{r}}$.
- $\mathrm{a}_{\mathrm{i}}$ are constant model parameters, defined as:

$\mathrm{a}_{1}=\frac{\mathrm{R}_{\mathrm{r}}}{\mathrm{k}}, \mathrm{a}_{2}=\frac{\mathrm{R}_{\mathrm{s}}+\left(\mathrm{R}_{\mathrm{r}} / \mathrm{k}^{2}\right)}{\mathrm{L}_{\mathrm{seq}}}$ and $\mathrm{a}_{3}=\frac{1}{\mathrm{~kL}_{\mathrm{seq}}}$ where $\mathrm{R}_{\mathrm{r}}$ and $\mathrm{R}_{\mathrm{s}}$ denote respectively the rotor and stator resistances; $\mathrm{k}$ is the transformation rate of the AC machine.

\section{HIGH GAIN OBSERVER DESIGN FOR INDUCTION MOTOR}

In this Section, a nonlinear observer is built-up, that estimates both the rotor flux and the stator current for induction motors. Such an observer is derived from model (1)-(3) that accounts for the nonlinear magnetic characteristics.

\subsection{Observer presentation}

It is assumed that the stator currents $\left(i_{s \alpha}, i_{s \beta}\right)$ and the rotor speed $(\omega)$ are the only measurable AC machine variables. In the $(\alpha, \beta)$-axes $\left(\omega_{\mathrm{s}}=0\right)$, the observation model (1) can be given the following more condensed state-affine representation:

$$
\begin{aligned}
& \dot{\mathrm{X}}=\mathrm{A}(\omega) \mathrm{X}+\varphi(\mathrm{u}, \mathrm{y}, \mathrm{X}) \\
& \mathrm{y}=\mathrm{CX}
\end{aligned}
$$

where :

$$
\begin{aligned}
& \mathrm{X}=\left[\mathrm{I}_{\mathrm{s}}^{\mathrm{T}}, \Psi_{\mathrm{r}}^{\mathrm{T}}\right]^{\mathrm{T}} \\
& I_{s}=\left[i_{s \alpha}, i_{s \beta}\right]^{T}, \Psi_{r}=\left[\phi_{r \alpha}, \phi_{r \beta}\right]^{T} \\
& y=\left[\begin{array}{lll}
i_{s \alpha} & i_{s \beta}
\end{array}\right]^{T}, u=\left[\begin{array}{ll}
v_{s \alpha} & v_{s \beta}
\end{array}\right]^{T}
\end{aligned}
$$

$\mathrm{A}(\omega), \varphi(\mathrm{u}, \mathrm{y}, \mathrm{X})$, are continuous functions defined by:

$$
\begin{aligned}
& \mathrm{A}(\omega)=\left[\begin{array}{cccc}
0 & 0 & \delta_{\mathrm{L}} & \mathrm{a}_{3} \omega \\
0 & 0 & -\mathrm{a}_{3} \omega & \delta_{\mathrm{L}} \\
0 & 0 & 0 & 0 \\
0 & 0 & 0 & 0
\end{array}\right]=\left[\begin{array}{cc}
0_{2} & \mathrm{~N}_{2}(\omega) \\
0_{2} & 0_{2}
\end{array}\right] \\
& \varphi(\mathrm{y}, \mathrm{u}, \mathrm{X})=\left[\begin{array}{c}
-\mathrm{a}_{2} \mathrm{I}_{\mathrm{s}}+\delta_{\mathrm{v}} \Psi_{\mathrm{r}}+\frac{1}{\mathrm{~L}_{\mathrm{seq}}} \mathrm{u} \\
\mathrm{a}_{1} \mathrm{I}_{\mathrm{s}}-\mathrm{kL}_{\mathrm{seq}} \delta \Psi_{\mathrm{r}}-\omega \mathfrak{J}_{2} \Psi_{\mathrm{r}}
\end{array}\right] \\
& \mathrm{C}=\left[\begin{array}{llll}
1 & 0 & 0 & 0 \\
0 & 1 & 0 & 0
\end{array}\right], \quad \mathfrak{J}_{2}=\left[\begin{array}{cc}
0 & 1 \\
-1 & 0
\end{array}\right]
\end{aligned}
$$

In (5), the positive parameter $\delta_{\mathrm{L}}$ denotes the constant value taken by the (varying) parameter $\delta(t)$ when the machine operates in the linear part of its magnetic characteristic. Then, one has:

$$
\delta(t)=\delta_{L}+\delta_{v}
$$

where $\delta_{v}$ denotes the varying component of $\delta(t)$.

With the above notations, the proposed high-gain observer can simply be formulated as follows:

$$
\dot{\hat{\mathrm{X}}}=\mathrm{A}(\omega) \hat{\mathrm{X}}+\varphi(\mathrm{u}, \mathrm{y}, \hat{\mathrm{X}})
$$




$$
+M(\omega)(C \hat{X}-y)
$$

and

$$
\hat{\delta}=W\left(\hat{\Phi}_{\mathrm{r}}\right)
$$

with $\hat{\Phi}_{\mathrm{r}}=\sqrt{\hat{\phi}_{\mathrm{r} \alpha}^{2}+\hat{\phi}_{\mathrm{r} \beta}^{2}}$

\subsection{Observer analysis.}

Introducing the state estimation error $\mathrm{e}=\mathrm{X}-\hat{\mathrm{X}}$, it follows from (4) and (9) that:

$\dot{\mathrm{e}}=(\mathrm{A}(\omega)-\mathrm{M}(\omega)) \mathrm{e}+\Lambda\left(\omega, \Psi_{\mathrm{r}}, \mathrm{e}\right)$

where: $\Lambda\left(\omega, \Psi_{\mathrm{r}}, \mathrm{e}\right) \stackrel{\text { def }}{=} \varphi(\mathrm{y}, \mathrm{u}, \mathrm{X})-\varphi(\mathrm{y}, \mathrm{u}, \hat{\mathrm{X}})$

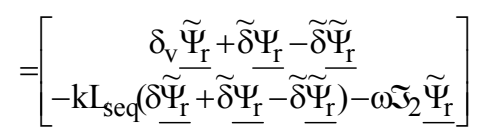

The observer analysis will make it clear how to choose $M(\omega)$ so that the error system (11) is asymptotically stable. This is the subject of the next Theorem, where the following notations are used:

$$
\begin{aligned}
& \Gamma=\left[\begin{array}{cc}
\mathrm{I}_{\mathrm{d} 2} & 0_{2} \\
0_{2} & \mathrm{~N}(\omega)
\end{array}\right], \Delta_{\theta}=\left[\begin{array}{cc}
\frac{1}{\theta} \mathrm{I}_{\mathrm{d} 2} & 0_{2} \\
0_{2} & \frac{1}{\theta^{2}} \mathrm{I}_{\mathrm{d} 2}
\end{array}\right] \\
& \overline{\mathrm{A}}=\left[\begin{array}{ll}
0_{2} & \mathrm{I}_{2} \\
0_{2} & 0_{2}
\end{array}\right]
\end{aligned}
$$

where $\theta$ is a positive real parameter. It can be easily checked that the pair $\{\overline{\mathrm{A}}, \mathrm{C}\}$ is observable since:

$$
\operatorname{rank}\left[\begin{array}{c}
\mathrm{C} \\
\mathrm{CA}
\end{array}\right]=\operatorname{dim} \mathrm{y}=2
$$

Then, there exists a matrix $\mathrm{K}$ of the form:

$\mathrm{K}=\left[\begin{array}{l}\mathrm{k}_{1} \mathrm{I}_{\mathrm{d} 2} \\ \mathrm{k}_{2} \mathrm{I}_{\mathrm{d} 2}\end{array}\right] \quad(\mathrm{k} 1$ and $\mathrm{k} 2$ positive real constants $)$

so that:

$$
\overline{\overline{\mathrm{A}}}=\overline{\mathrm{A}}-\mathrm{KC}
$$

be a Hurwitz matrix. This implies the existence of a unique symmetric positive definite matrix $P$ satisfying the following (Lyapunov) equation:

$$
\mathrm{P}(\overline{\mathrm{A}}-\mathrm{KC})+(\overline{\mathrm{A}}-\mathrm{KC})^{\mathrm{T}} \mathrm{P}=-\mathrm{I}_{4}
$$

Now we are in a position to establish the main result of the paper.

Theorem 1: Consider the model (1) and assume that the rotor speed $\omega$ and its time-derivative remain bounded. To estimate the state vector X, consider the observer (9) with the matrix gain $\mathrm{M}(\omega)$ of the form:

$$
\mathrm{M}(\omega)=\Gamma^{-1}(\omega) \Delta_{\theta}^{-1} \mathrm{~K}
$$

and let the parameter $\theta$ in (16) be chosen such that:

$\theta>2\|\mathrm{P}\|\left(\mathrm{L}_{\Gamma^{-1}}+\mathrm{cL}_{\Gamma} \mathrm{L}_{\Gamma^{-1}}\right)$

where:

$$
\mathrm{L}_{\dot{\Gamma} \Gamma^{-1}}=\sup _{\omega \in \mathrm{K}}\left\|\dot{\Gamma}(\omega) \Gamma^{-1}(\omega)\right\|
$$

$$
\begin{aligned}
& \mathrm{L}_{\Gamma}=\sup _{\omega \in \mathrm{K}}\|\Gamma(\omega)\|, \mathrm{L}_{\Gamma^{-1}}=\sup _{\omega \in \mathrm{K}}\left\|\Gamma^{-1}(\omega)\right\| \\
& \mathrm{L}_{\theta}=\sup \left(\frac{1}{\theta}, \frac{1}{\theta^{2}}\right), \mathrm{L}_{\theta^{-1}}=\sup \left(\theta, \theta^{2}\right)
\end{aligned}
$$

Then, one has the following results:

The observation error system (11) is locally asymptotically stable and the size of its attraction region depends on the choice of the parameters $\theta, \mathrm{k}_{1}$ and $k_{2}$. Consequently, if the initial value of the observation error $\mathrm{e}=\left[\tilde{\mathrm{i}}_{\mathrm{s} \alpha}, \widetilde{\mathrm{i}}_{\mathrm{s} \beta}, \widetilde{\phi}_{\mathrm{r} \alpha}, \widetilde{\phi}_{\mathrm{r} \beta}\right]^{\mathrm{T}}$ belongs to the attraction region, e converges to zero.

Proof: From (5) and (13), one gets:

$$
\begin{aligned}
& \Gamma(\omega) \Delta_{\theta} \mathrm{A}(\omega)\left(\Gamma(\omega) \Delta_{\theta}\right)^{-1}=\theta \overline{\mathrm{A}}, \\
& \mathrm{C}\left(\Gamma(\omega) \Delta_{\theta}\right)^{-1}=\theta \mathrm{C}
\end{aligned}
$$

As in (De Leon et al, 2001), let us introduce the following modified error variable:

$\varepsilon=\Gamma(\omega) \Delta_{\theta} \mathrm{e}$

Then, using (19)-(20), it follows from (11) that $\varepsilon$ satisfies the following equation:

$$
\begin{aligned}
& \dot{\varepsilon}=\theta \overline{\overline{\mathrm{A}}} \varepsilon+\Gamma(\omega) \Delta_{\theta} \Lambda\left(\omega, \Psi_{\mathrm{r}}, \mathrm{e}\right) \\
& +\dot{\Gamma}(\omega) \Gamma^{-1}(\omega) \varepsilon
\end{aligned}
$$

To analyze the stability of system (21), let us consider the following Lyapunov function candidate $\mathrm{V}=\varepsilon^{\mathrm{T}} \mathrm{P} \varepsilon$. Its time-derivation along the trajectory of (21) yields:

$$
\begin{aligned}
& \dot{\mathrm{V}}=\theta \varepsilon^{\mathrm{T}}\left[\mathrm{P} \overline{\overline{\mathrm{A}}}+\overline{\overline{\mathrm{A}}}^{\mathrm{T}} \mathrm{P}\right] \varepsilon+2 \varepsilon^{\mathrm{T}} \mathrm{P} \Gamma(\omega) \Delta_{\theta} \Lambda\left(\omega, \Psi_{\mathrm{r}}, \mathrm{e}\right) \\
& +2 \varepsilon^{\mathrm{T}} \mathrm{P} \dot{\Gamma}(\omega) \Gamma^{-1}(\omega) \varepsilon
\end{aligned}
$$

Let us focus on the second term in the right side of (22), which is the only one, not quadratic function of $\varepsilon$. First, an upper bound on the quantity $\Lambda\left(\omega, \Psi_{\mathrm{r}}, \mathrm{e}\right)$ will be determined. To this end, one needs the following technical proposition (proof given in Appendix).

Proposition 1. Let $\widetilde{\delta} \stackrel{\text { def }}{=} \delta(\mathrm{t})-\hat{\delta}$ and $\Phi_{\mathrm{rmax}}$ be the maximum value of $\Phi_{\mathrm{r}}$, (which exists because $\Phi_{\mathrm{r}}$ is bounded). Then, $|\widetilde{\delta}|$ can be upper bounded as follows:

$$
|\widetilde{\delta}| \leq\left(\mathrm{h}_{1}\left\|\widetilde{\Psi}_{\mathrm{r}}\right\|+\mathrm{h}_{2}\left\|\widetilde{\Psi}_{\mathrm{r}}\right\|^{\mathrm{p}}\right)
$$

for some positive real constants $h_{1}$ and $h_{2}$.

On the other hand, as the model parameter $\delta(t)$ is a continuous function of the real flux norm flux (2)(3), there exists a positive real constant $\delta_{\max }$ such that:

$$
\delta(\mathrm{t}) \leq \delta_{\max } \quad \text { and } \quad \delta_{\mathrm{v}} \leq \delta_{\max }-\delta_{\mathrm{L}}
$$

Now, using inequalities (23)-(24) and the fact that the rotor speed is bounded, it follows from (12) that: 


$$
\begin{array}{r}
\Lambda\left(\omega, \Psi_{\mathrm{r}}, \mathrm{e}\right)=\left[\begin{array}{c}
\delta_{\mathrm{v}} \mathrm{I}_{\mathrm{d} 2} \\
-\mathrm{kL}_{\mathrm{seq}} \delta \mathrm{I}_{\mathrm{d} 2}
\end{array}\right] \widetilde{\Psi}_{\mathrm{r}}+\widetilde{\delta}\left[\begin{array}{c}
\mathrm{I}_{\mathrm{d} 2} \\
-\mathrm{kL}_{\mathrm{seq}} \mathrm{I}_{\mathrm{d} 2}
\end{array}\right] \Psi_{\mathrm{r}} \\
-\widetilde{\delta}\left[\begin{array}{c}
\mathrm{I}_{\mathrm{d} 2} \\
-\mathrm{kL}_{\mathrm{seq}} \mathrm{I}_{\mathrm{d} 2}
\end{array}\right] \widetilde{\Psi}_{\mathrm{r}}-\omega\left[\begin{array}{c}
0_{2} \\
\mathfrak{J}_{2}
\end{array}\right] \widetilde{\Psi}_{\mathrm{r}} \\
\left\|\Lambda\left(\omega, \Psi_{\mathrm{r}}, \mathrm{e}\right)\right\| \leq
\end{array}
$$

with:

$\mathrm{c}_{0}=\left\|\left[\begin{array}{c}\delta_{\mathrm{v} \max } \mathrm{I}_{\mathrm{d} 2} \\ -\mathrm{kL}_{\mathrm{seq}} \delta_{\max } \mathrm{I}_{\mathrm{d} 2}-\omega_{\max } \widetilde{J}_{2}\end{array}\right]\right\|, \mathrm{c}_{1}=\left\|\left[\begin{array}{c}\mathrm{I}_{\mathrm{d} 2} \\ -\mathrm{kL}_{\mathrm{seq}} \mathrm{I}_{\mathrm{d} 2}\end{array}\right]\right\|$

and some generic positive real constant $\mathrm{h}$ depending on known parameters, namely $\Phi_{r \max }$ and the coefficients $b_{i}(i=1, \ldots, p)$ of $W($.) given in (3).

Then, the second term on the right side of (22) can be upper bounded, using (25), by :

$$
\begin{aligned}
\left\|\Gamma \Delta_{\theta} \Lambda\right\| & \leq \mathrm{L}_{\Gamma} \mathrm{cL}_{\Gamma^{-1}}\|\varepsilon\| \\
& +\mathrm{hL}_{\Gamma}\left(\mathrm{L}_{\theta^{-1}}\right)^{\mathrm{p}}\left(\mathrm{L}_{\Gamma^{-1}}\right)^{\mathrm{p}+1}\|\varepsilon\|^{\mathrm{p}+1}
\end{aligned}
$$

where

$$
\mathrm{c}=\mathrm{c}_{0}+\mathrm{c}_{1} \mathrm{~h}_{1} \Phi_{\mathrm{r} \max }
$$

Now using (26) and (18), it follows from (22) that:

$$
\begin{aligned}
\dot{\mathrm{V}} & \leq-\theta\|\varepsilon\|^{2}+2\|\mathrm{P}\|\left(\mathrm{cL}_{\Gamma} \mathrm{L}_{\Gamma^{-1}}+\mathrm{L}_{\dot{\Gamma}^{-1}}\right)\|\varepsilon\|^{2} \\
& +2\|\mathrm{P}\| \mathrm{L}_{\Gamma} \mathrm{h}\left(\mathrm{L}_{\theta^{-1}}\right)^{\mathrm{p}}\left(\mathrm{L}_{\Gamma^{-1}}\right)^{\mathrm{p}+1}\|\varepsilon\|^{\mathrm{p}+2}
\end{aligned}
$$

Then, using the fact that $\mathrm{V}=\varepsilon^{\mathrm{T}} \mathrm{P} \varepsilon$, inequality (28) implies:

$$
\begin{aligned}
\dot{\mathrm{V}} & \leq-\lambda_{\min }^{-1}(\mathrm{P})\left(\theta-2\|\mathrm{P}\|\left(\mathrm{L}_{\Gamma^{-1}}+\mathrm{cL}_{\Gamma} \mathrm{L}_{\Gamma^{-1}}\right)\right) \mathrm{V} \\
& +2 \mathrm{~h}\|\mathrm{P}\| \mathrm{L}_{\Gamma}\left(\mathrm{L}_{\Gamma^{-1}}\right)^{\mathrm{p}+1}\left(\mathrm{~L}_{\theta^{-1}}\right)^{\mathrm{p}} \lambda_{\max }^{-\mathrm{p}-2}(\mathrm{P}) \mathrm{V}^{\frac{\mathrm{p}}{2}+1}
\end{aligned}
$$

where $\lambda_{\min }(\mathrm{P})$ and $\lambda_{\max }(\mathrm{P})$ denote respectively the smallest and the largest eigenvalues of the positive definite matrix $P$.

It follows from (29) that if

$$
\theta>2\|\mathrm{P}\|\left(\mathrm{L}_{\Gamma^{-1}}+\mathrm{cL}_{\Gamma} \mathrm{L}_{\Gamma^{-1}}\right)
$$

then one has:

$$
\dot{\mathrm{V}} \leq-\alpha \mathrm{V}+\beta \mathrm{V}^{\frac{\mathrm{p}}{2}+1}
$$

where:

$$
\begin{gathered}
\alpha=\left(\theta-2\|\mathrm{P}\|\left(\mathrm{L}_{\dot{\Gamma} \Gamma^{-1}}+\mathrm{cL}_{\Gamma} \mathrm{L}_{\Gamma^{-1}}\right)\right) \lambda_{\min }^{-1}(\mathrm{P}) \\
\beta=2 \mathrm{~h}\|\mathrm{P}\| \mathrm{L}_{\Gamma}\left(\mathrm{L}_{\Gamma^{-1}}\right)^{\mathrm{p}+1}\left(\mathrm{~L}_{\theta^{-1}}\right)^{\mathrm{p}}\left(\lambda_{\max }(\mathrm{P})\right)^{-\mathrm{p}-2}
\end{gathered}
$$

and $h$ is a generic positive real constant depending on the machine characteristics i.e.

$$
\mathrm{h}=\text { function of }\left(\mathrm{W}(.), \Phi_{\mathrm{r} \text { max }}, \mathrm{k}, \mathrm{L}_{\mathrm{seq}}\right)
$$

Let us introduce the functions $\mathrm{g}_{1}(\mathrm{~V})=\mathrm{aV}$ and

$$
\mathrm{g}_{2}(\mathrm{~V})=\mathrm{bV}^{\left(\frac{\mathrm{p}}{2}+1\right)}
$$

They are plotted in Figure 1 which clearly shows that if $\mathrm{V}(0)$ belongs to the interval $\left[0, \mathrm{~V}_{\mathrm{A}}\right]$, then $\dot{V}$ will still be negative as long as $\mathrm{V}(\mathrm{t})$ is nonzero. Thus, $\mathrm{V}(\mathrm{t})$ should vanish asymptotically. The parameter $\mathrm{V}_{\mathrm{A}}$ which define the size of the attraction region is explicitly given by:

$$
\mathrm{V}_{\mathrm{A}}=\left(\frac{\mathrm{a}}{\mathrm{b}}\right)^{\frac{2}{\mathrm{p}}}
$$

Equation (31) shows that the size of the attraction region depends of a which in turn depends on $\theta$.

This ends the proof of the Theorem.

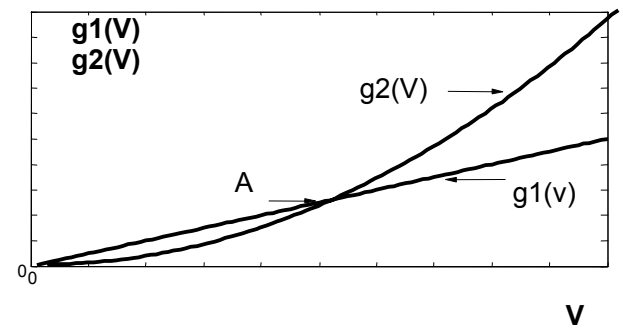

Fig1: Fonctions g1(V) and g2(V)

\section{SIMULATION}

The performances of the observer (9) are illustrated, in this section, using the experimentally validated model (Ouadi et al, 2004a) to represent the true machine. Recall that such a model corresponds to a $7.5 \mathrm{KW}$ induction motor. The simulation protocol is designed in such a way that the machine operates around different points of its magnetic characteristic at different rotor speeds and different load torque values. To this end, the load torque and the stator current pulsation speed are chosen as shown by figures $2 \mathrm{a}-\mathrm{b}$. The resulting rotor speed and model parameter $\delta(t)$ are given in figures $3 a-b$. Notice that the parameter $\delta(t)$ takes different values depending on the flux amplitude. The other simulation features are the following:

- The machine is open-loop controlled using a sinusoid stator voltage input (amplitude $\mathrm{V}_{\mathrm{s}}=150 \mathrm{~V}$ ).

- The initial conditions of the observer are quite different from those of the true system:

$$
\hat{\Phi}_{\mathrm{r}}(0)=0.9(\mathrm{wb}), \quad \Phi_{\mathrm{r}}(0)=0.15(\mathrm{wb})
$$

- Bearing in mind condition (14) and (17), the observer gains are chosen as $\mathrm{k}_{1}=10, \mathrm{k}_{2}=1$ and $\theta=100$.

Figures 4a-d shows that the observer (9) performs as well in the linear part of the magnetic characteristic (which is the case for $t \in[0,5 \mathrm{~s}]$ when $\Phi_{\mathrm{r}} \leq 0.75 \mathrm{~Wb}$ ), as in the nonlinear part (which is the case for $\mathrm{t} \in[5 \mathrm{~s}, 10 \mathrm{~s}]$, when $\left.\Phi_{\mathrm{r}}>0.75 \mathrm{~Wb}\right)$. The flux and current estimates converge to their true values after a transient period that lasts less than 0.4 second. 


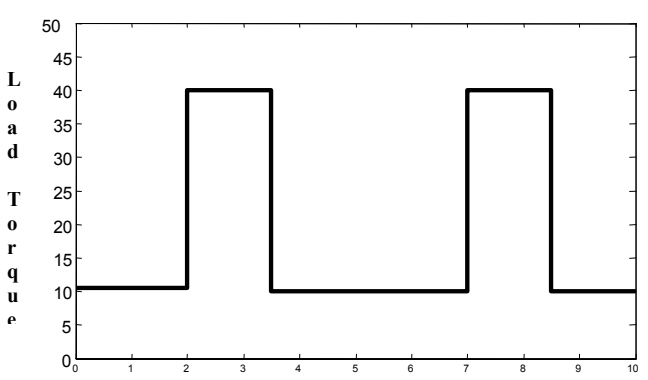

time

Fig.2a. Load torque (Nm)

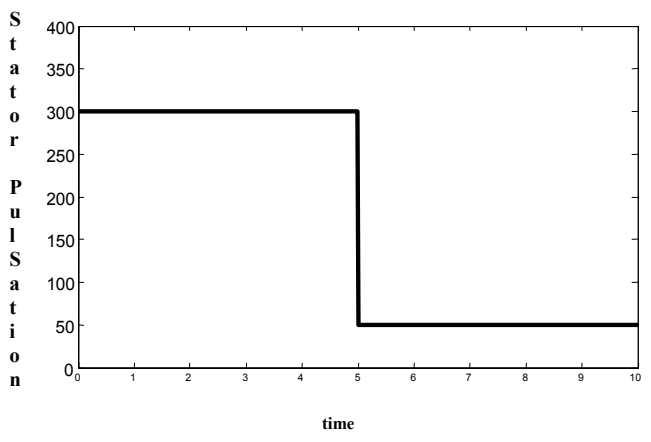

Fig.2b. Stator current pulsation

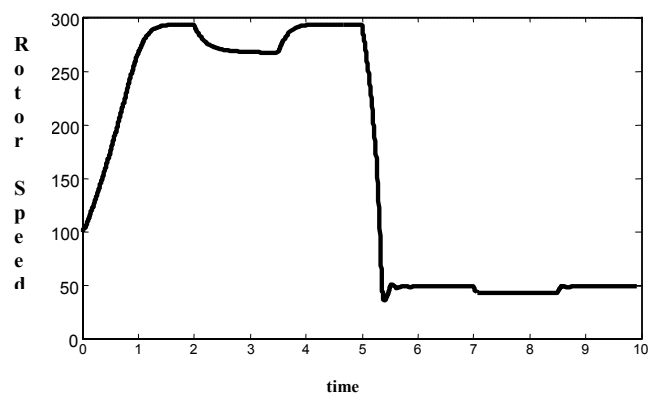

Fig.3a. Rotor speed. (rd/s)

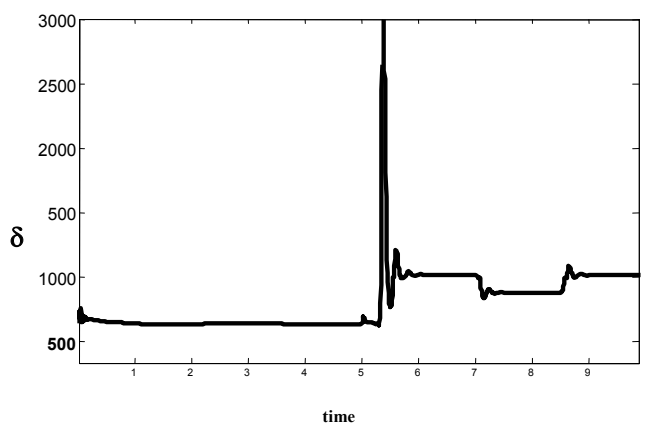

Fig.3b. Model parameter $\delta(\mathrm{t})$

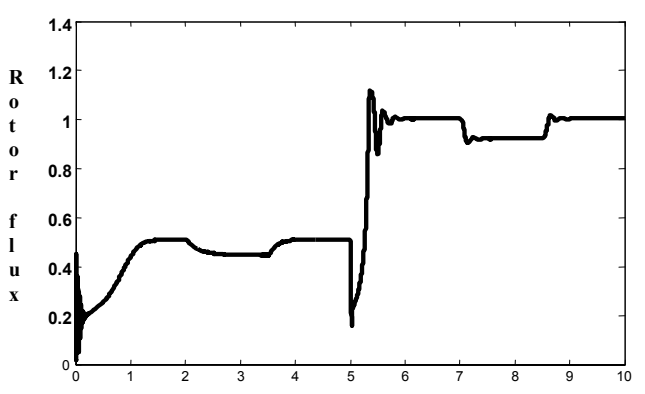

time

Fig.4a. Observer performances for $\theta=100$. Flux norm estimation (wb)

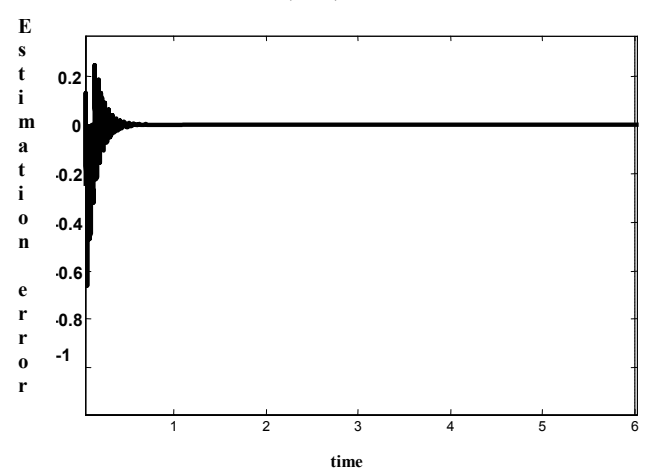

Fig. 4b. Flux estimation error (wb)

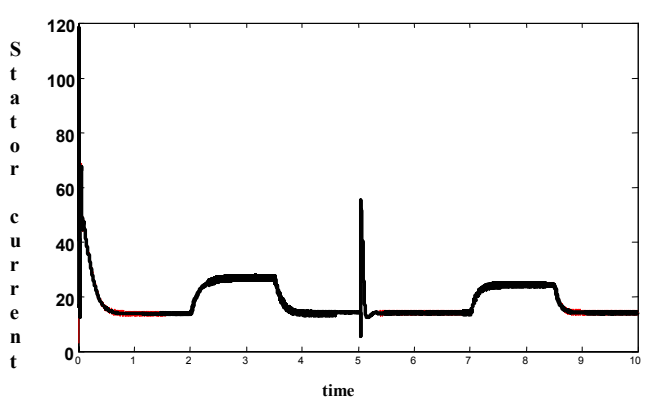

Fig.4c. Observer performances for $\theta=100$. Stator current norm estimation (dotted) and reel (solid)

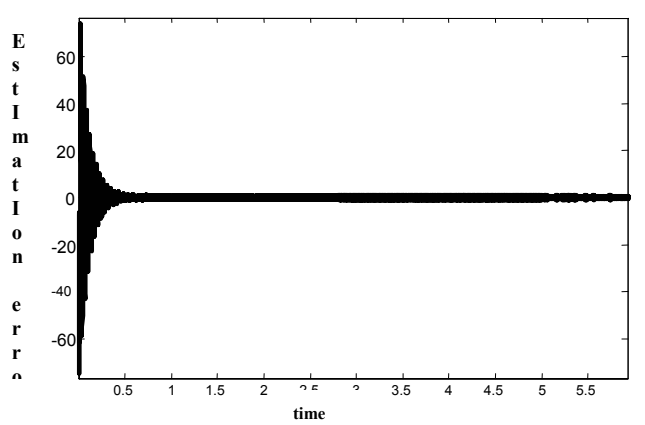

Fig.4d. Stator current estimation error. (A)

To emphasize the performances of the observer (9) it is compared with simple observers designed from the standard model, which neglects the saturating feature of the machine magnetic characteristic. Such observers (e.g. Pietrzak, et al, 1992; De Leon, et al, 
2001) are obtained by setting the parameter $\delta(t)$ to be a constant value. For the machine studied in (Ouadi et al, 2004b), this value, in the linear part of the magnetic characteristic, is 935 (see Fig 3.b for $t \in[0,5 \mathrm{~s}])$.

Figure 5 compares the performances of the $\delta$ varying observer $(9)$ and its simplified version $(\delta(t)$ $\left.=\delta_{\mathrm{L}}=935\right)$. The simulation protocol is the same as previously. It is seen that both observers behave as well as the machine operates in the linear zone, which is the case when the flux is at its low level, i.e. $\Phi r<0.75 \mathrm{~Wb}$. However, when the machine operates in the nonlinear zone (flux larger than $0.75 \mathrm{~Wb}$ ), the $\delta$-varying observer behaves much better. Indeed, it is seen from fig 5 that there is a relative flux estimation error for the $\delta$-constant observer of about $40 \%$.

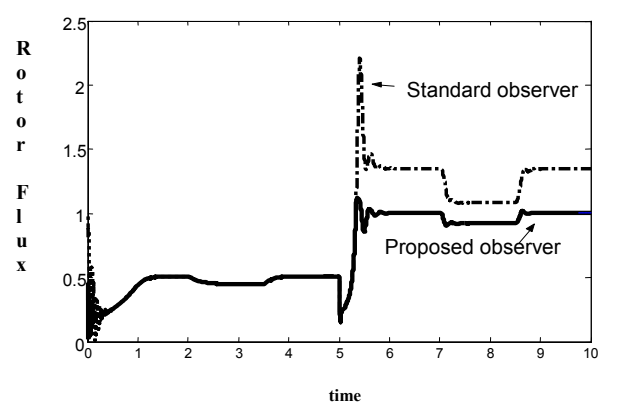

Fig.5. Rotor flux norm. Standard observer (dashed), proposed observer (dotted) and reel (solid). (wb)

\section{REFERENCES}

Barbot. J. P, Djemai. M, T. Boukhobza, and A. Glumineau, (2000) 'Observateur non linéaire de type Mode glissants: Application à la machine asynchrone', in Commande des moteurs asynchrones, (Hermès) pp. 219-284, Vol 2.

De Leon J., Alvarez-Leal J. G., Castro- Linares R., and Alvarez-Gallegos J. (2001) "Control of a flexible joint robot manipulator via a nonlinear control-observer scheme" International Journal of Control, 74(3): 290-302.

Leonhard. W, (1985) 'Control of Electrical Drives', (New-York: Springer-Verlag)

Lubineau. D, Dion. J. M, Dugard. L and Roye. D, (1999) 'Design of an advanced nonlinear controller for induction motor and experimental validation on an industrial benchmark', EPJ Applied Physics, Vol 9, pp. 967-98

Ouadi. H, Giri. F and Dugard. L, (2004a) 'Accounting for magnetic saturation in modeling AC machines. Theoretical development and experimental validation', IEEE Conference on Control Applications, Tapeï, Taïwan, sept. 2004

Ouadi. H, Giri. F and Dugard. L, (2004b) 'Accounting for magnetic characteristic nonlinearity in Designing induction motor observer', Symposium on Non Linear Control Systems NOLCOS,-Stuttgart.

\section{APPENDIX A}

From (2) and (10), it follows that:

$$
\begin{aligned}
\widetilde{\delta}= & \mathrm{b}_{1}\left(\Phi_{\mathrm{r}}-\hat{\Phi}_{\mathrm{r}}\right)+\mathrm{b}_{2}\left(\Phi_{\mathrm{r}}^{2}-\hat{\Phi}_{\mathrm{r}}^{2}\right)+\mathrm{b}_{3}\left(\Phi_{\mathrm{r}}^{3}-\hat{\Phi}_{\mathrm{r}}^{3}\right) \cdots \\
& +\mathrm{b}_{\mathrm{p}}\left(\Phi_{\mathrm{r}}^{\mathrm{p}}-\hat{\Phi}_{\mathrm{r}}^{\mathrm{p}}\right)
\end{aligned}
$$

Substituting $\Phi_{\mathrm{r}}-\widetilde{\Phi}_{\mathrm{r}}$ to $\hat{\Phi}$ in the right side of (32), yields:

$$
\begin{aligned}
\widetilde{\delta}=b_{1} & \widetilde{\Phi}_{\mathrm{r}}+\mathrm{b}_{2}\left(\Phi_{\mathrm{r}}^{2}-\left(\Phi_{\mathrm{r}}-\widetilde{\Phi}_{\mathrm{r}}\right)^{2}\right)+\mathrm{b}_{3}\left(\Phi_{\mathrm{r}}^{3}-\left(\Phi_{\mathrm{r}}-\widetilde{\Phi}_{\mathrm{r}}\right)^{3}\right) \cdots \\
& +\mathrm{b}_{\mathrm{p}}\left(\Phi_{\mathrm{r}}^{\mathrm{p}}-\left(\Phi_{\mathrm{r}}-\widetilde{\Phi}_{\mathrm{r}}\right)^{\mathrm{p}}\right)
\end{aligned}
$$

Now, for any integer $\mathrm{k}$, one has the well known identity:

$$
\begin{aligned}
& \left(\Phi_{\mathrm{r}}-\widetilde{\Phi}_{\mathrm{r}}\right)^{\mathrm{k}}=\mathrm{C}_{\mathrm{k}}^{0} \Phi_{\mathrm{r}}^{\mathrm{k}}-\mathrm{C}_{\mathrm{k}}^{1} \Phi_{\mathrm{r}}^{\mathrm{k}-1} \widetilde{\Phi}_{\mathrm{r}}+\mathrm{C}_{\mathrm{k}}^{2} \Phi_{\mathrm{r}}^{\mathrm{k}-2} \widetilde{\Phi}_{\mathrm{r}}^{2}+\cdots \\
& +(-1)^{\mathrm{j}+1} \mathrm{C}_{\mathrm{k}}^{\mathrm{j}} \Phi_{\mathrm{r}}^{\mathrm{k}-\mathrm{j}} \widetilde{\Phi}_{\mathrm{r}}^{\mathrm{j}}+\cdots+(-1)^{\mathrm{k}+1} \mathrm{C}_{\mathrm{k}}^{\mathrm{k}} \widetilde{\Phi}_{\mathrm{r}}^{\mathrm{k}}
\end{aligned}
$$

Applying (34) to the relevant terms in (33) gives:

$$
\widetilde{\delta}=\sum_{\mathrm{k}=1}^{\mathrm{p}}(-1)^{\mathrm{k}+1}\left(\sum_{\mathrm{j}=\mathrm{k}}^{\mathrm{p}} \mathrm{b}_{\mathrm{j}} \mathrm{C}_{\mathrm{j}}^{\mathrm{k}} \Phi_{\mathrm{r}}^{\mathrm{j}-\mathrm{k}}\right) \widetilde{\Phi}_{\mathrm{r}}^{\mathrm{k}}
$$

As $\left|\Phi_{\mathrm{r}}\right| \leq \Phi_{\mathrm{rmax}}$, it follows that:

$$
\begin{aligned}
|\widetilde{\delta}| & \leq \sum_{k=1}^{p}\left(\sum_{j=k}^{p}\left|b_{j}\right| C_{j}^{k}\left(\Phi_{r \text { max }}\right)^{j-k}\right)\left|\widetilde{\Phi}_{r}\right|^{k} \\
\leq & \left(\sum_{j=1}^{n}\left|b_{j}\right| C_{j}^{1}\left(\Phi_{r \text { max }}\right)^{j-1}\right)\left|\widetilde{\Phi}_{r}\right| \\
& +\left[\sum_{k=2}^{n}\left(\sum_{j=k}^{n}\left|b_{j}\right| C_{j}^{k}\left(\Phi_{r \max }\right)^{j-k}\right]\left[\left|\widetilde{\Phi}_{r}\right|+\left|\widetilde{\Phi}_{r}\right|^{n}\right]\right. \\
\leq & h_{1}\left|\widetilde{\Phi}_{r}\right|+h_{2}\left|\widetilde{\Phi}_{r}\right|^{p}
\end{aligned}
$$

where:

$$
\begin{aligned}
& \mathrm{h}_{1} \stackrel{\text { def }}{=}\left[\sum_{\mathrm{k}=1}^{\mathrm{p}}\left(\sum_{\mathrm{j}=\mathrm{k}}^{\mathrm{p}}\left|\mathrm{b}_{\mathrm{j}}\right| \mathrm{C}_{\mathrm{j}}^{\mathrm{k}}\left(\Phi_{\mathrm{r} \text { max }}\right)^{\mathrm{j}-\mathrm{k}}\right)\right] \\
& \mathrm{h}_{2} \stackrel{\operatorname{def}}{=}\left[\sum_{\mathrm{k}=2}^{\mathrm{p}}\left(\sum_{\mathrm{j}=\mathrm{k}}^{\mathrm{p}}\left|\mathrm{b}_{\mathrm{j}}\right| \mathrm{C}_{\mathrm{j}}^{\mathrm{k}}\left(\Phi_{\mathrm{r} \text { max }}\right)^{\mathrm{j}-\mathrm{k}}\right]\right]
\end{aligned}
$$

Furthermore, as $\quad \widetilde{\Phi}_{\mathrm{r}}=\sqrt{\phi_{\mathrm{r} \alpha}^{2}+\phi_{\mathrm{r} \beta}^{2}}-\sqrt{\hat{\phi}_{\mathrm{r} \alpha}^{2}+\hat{\phi}_{\mathrm{r} \beta}^{2}} \quad$ it follows, using simple calculations, that:

$$
\begin{aligned}
\left|\widetilde{\phi}_{\mathrm{r}}\right| & =\left|\frac{\phi_{\mathrm{r} \alpha}^{2}-\hat{\phi}_{\mathrm{r} \alpha}^{2}+\phi_{\mathrm{r} \beta}^{2}-\hat{\phi}_{\mathrm{r} \beta}^{2}}{\sqrt{\phi_{\mathrm{r} \alpha}^{2}+\phi_{\mathrm{r} \beta}^{2}}+\sqrt{\hat{\phi}_{\mathrm{r} \alpha}^{2}+\hat{\phi}_{\mathrm{r} \beta}^{2}}}\right| \\
& \leq\left|\widetilde{\phi}_{\mathrm{r} \alpha}\right|+\left|\widetilde{\phi}_{\mathrm{r} \beta}\right| \leq\left\|\widetilde{\Psi}_{\mathrm{r}}\right\|
\end{aligned}
$$

Using (37), it follows from (36) that:

$$
|\widetilde{\delta}| \leq\left(\mathrm{h}_{1}\left\|\widetilde{\Psi}_{\mathrm{r}}\right\|+\mathrm{h}_{2}\left\|\widetilde{\Psi}_{\mathrm{r}}\right\|^{\mathrm{p}}\right)
$$

